\title{
Ut pictura poesis y la construcción espaciotemporal de las imágenes literarias en El divino Narciso de sor Juana Inés de la Cruz

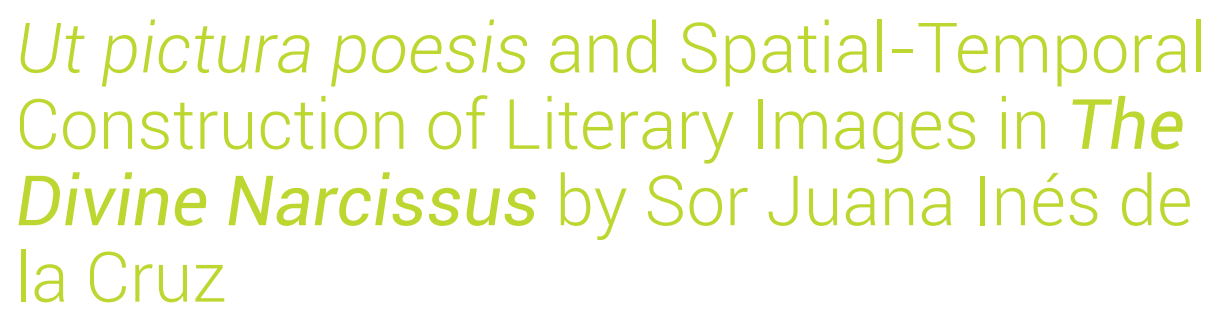

\section{Robin Ann Rice}

Universidad Popular Autónoma del Estado de Puebla MÉXICO

niborecir@hotmail.com

[Hipogrifo, (issn: 2328-1308), 6.1, 2018, pp. 163-177]

Recibido: 11-11-2016 / Aceptado: 28-12-2016

DOI: Rice: http://dx.doi.org/10.13035/H.2018.06.01.12

Resumen. En contraposición a las teorías tradicionales sobre el lenguaje, este artículo propone que la presencia de Ut pictura poesis textual denota una literatura ilustrativa que se comprende sincrónicamente y, por lo tanto, produce un constructo espaciotemporal. El propósito del estudio es el de examinar El divino Narciso de sor Juana Inés de la Cruz y analizar ciertas técnicas empleadas tales como imágenes literarias plásticas, en particular, los bloques alegóricos, los emblemas y las evocaciones de imágenes tan reconocidas que con una simple mención de su tema, los espectadores habrían podido recrearlas en su imaginación gracias a procesos cognitivos espaciotemporales.

Palabras clave. Ut pictura poesis; sor Juana Inés de la Cruz; El divino Narciso.

Abstract. In contrast with traditional linguistic theories, this article proposes that the presence of Ut pictura poesis in a text indicates that it is illustrative literature, synchronically comprehended, and, thus, produces a space-time construct. The purpose of this study is to examine El divino Narciso by sor Juana Inés de la Cruz 
and to analyze certain techniques used such as plastic literary imagery, allegorical units, emblems and the evocation of images that were so familiar to the audience that a simple mention of them would have allowed for a mental recreation of them by means of space-time cognitive processes.

Keywords. Ut pictura poesis; sor Juana Inés de la Cruz; El divino Narciso.

Ut pictura poesis: la pintura es poesía muda y la poesía, una pintura hablada, acuñada por los antiguos, no fue estimada plenamente hasta el Renacimiento. Tanto Aristóteles como Horacio formularon analogías novedosas entre la literatura y la pintura pero la verdadera 'invención' de las «artes hermanas»', como las consideramos hoy, es un concepto arraigado más en el Renacimiento y el Barroco que en la Antigüedad. La capacidad literaria de crear imágenes tan claras como una pintura era el eslabón principal que unía el quehacer del poeta con el del pintor. Este estudio es un acercamiento teórico y práctico a la ekphrasis o Ut pictura poesis, su funcionamiento y la identificación de ella en el auto sacramental, El divino Narciso de sor Juana Inés de la Cruz. Mi hipótesis es que este auto sacramental está compuesto por una gran cantidad de imágenes literarias plásticas, en particular, los bloques alegóricos, los emblemas y las evocaciones de imágenes tan reconocidas que con una simple mención de su tema, los espectadores habrían podido recrearlas en su imaginación. Todos estos se caracterizan por ser reconstrucciones espaciotemporales. Combinan las modalidades espaciales de la pintura con las temporales de la literatura para crear una poesía pictórica. Por medio del análisis de la compostura de estas imágenes en la obra, pretendo comprobar que el texto sorjuanino es una composición plástica que adquiere su aspecto espaciotemporal por medio de una conceptualización sincrónica. Se explorará cómo se distingue entre el lenguaje figurativo plástico que ejemplifica el concepto de Ut pictura poesis y el lenguaje poético menos plástico, menos propenso a crear una pintura hablada. Se discutirá la diferencia entre el lenguaje representativo y el ilustrativo en el auto sacramental y se dará ejemplos de los dos. Por fin, se examinarán las diferencias entre el lenguaje metafórico representativo y el lenguaje metafórico ilustrativo: el primero es narrativo y el segundo es una acumulación de imágenes que crean un cuadro mental espacial.

Tradicionalmente, se profesaba que el lenguaje se desplazaba y se entendía en el tiempo, secuencialmente, mientras que las artes plásticas se percibían en el espacio. Este pensamiento tradicional se manifestó en Arnheim:

El pensamiento intelectual [...] orienta los conceptos perceptuales en sucesión lineal. [...] El pensamiento intelectual desmantela la simultaneidad de la estructura espacial. [...] El lenguaje se utiliza linealmente porque cada palabra o conglomerado de palabras alude a un concepto intelectual, y tales conceptos sólo pueden combinarse en sucesión. [...] la interacción simultánea no puede ser descrita di- 
rectamente en el lenguaje, y es difícil transmitir mediante palabras el efecto de tal interacción? ${ }^{2}$.

En oposición directa con el planteamiento expresado en este estudio, Arnheim continua con el dictamen: «Si la poesía -y en esto se incluye toda forma de lenguaje- emprende en cambio la tarea de describir una situación visual mediante sus partes, la mente es a menudo incapaz de integrarlas en una imagen fija» ${ }^{3}$. En efecto, el filósofo niega la posibilidad de una conjuración lingüística espacial. En contraste con Arnheim, Joseph Frank examinó ampliamente el concepto de lo espacial lingüístico en sus textos canónicos The Widening Gyre (1963) y The Idea of Spatial Form (1991), razonamientos que se usarán en este estudio para comprobar la hipótesis y para el análisis de El divino Narciso. La investigación de Frank explora este fenómeno en Eliot, Pound, Proust y Joyce, entre otros. Sin embargo, la utilización plena de Ut pictura poesis se afianzó en el Siglo de Oro y por esto, el propósito de este estudio es revisar la manera en qué se construyen las imágenes en El divino Narciso de sor Juana Inés de la Cruz utilizando la teoría de Frank.

\section{REPRESENTACIÓN VS. ILUSTRACIÓN}

La conexión entre el ente literario y la realidad es o representativa o ilustrativa. Las imágenes en una narrativa o intentan replicar la realidad o pretenden recordarnos solo unos aspectos selectos de la realidad. El arte literario o plástico que aspira a duplicar la realidad se denomina arte representativo. El arte que ambiciona sugerir solamente un aspecto de la realidad se designa como ilustrativo. El arte ilustrativo es estilizado y su significado es concertado y dependiente de tradiciones y convenciones artísticas. El ilustrativo es simbólico y el representativo es miméti$\mathrm{CO}^{4}$. La literatura y las artes imitan la realidad usando medios distintos. La pintura utiliza la forma y el color en el espacio mientras que la literatura se fabrica de sonidos articulados en el tiempo. Ezra Pound, poeta y teórico principal del Imaginismo, reesquematizó el concepto de la creación de una imagen con la siguiente definición. Según el poeta ${ }^{5}$, una imagen literaria es la que presenta un objeto intelectual y emocional en un instante de tiempo. Es decir, una imagen no es definida como una reproducción pictórica sino como la unificación de ideas y emociones dispares en un complejo presentado espacialmente en un instante de tiempo. Tal complejo no se traslada discursivamente según las leyes del lenguaje, sino impacta la sensibilidad del lector instantáneamente ${ }^{6}$. 


\section{EL FUNCIONAMIENTO DE DIACRONÍA Y SINCRONÍA EN LA ESPACIALIDAD LITERARIA}

La lectura es una actividad que se desarrolla en el tiempo secuencialmente y por esto es un proceso diacrónico. Por otro lado, la observación de una pintura es una acumulación de información visual y es sincrónica. La literatura ilustrativa crea una espacialidad y apela a una lectura sincrónica. La construcción de las imágenes por parte del lector en la literatura altamente estilizada requiere que se suspenda temporalmente la comprensión de referencias individuales hasta que el patrón entero de referencias internas se pueda aprehender como una unidad. Culmina en la autonegación del lenguaje y la creación de un poema pictográfico híbrido?. Las relaciones sincrónicas dentro de este tipo de textos predominan sobre la referencialidad diacrónica. El poema es comprensible únicamente cuando el patrón de relaciones sincrónicas haya sido construido .

El auto sacramental barroco es una acumulación de imágenes, por lo general, alegorías y emblemas, y la trama o narración de acciones toma un segundo lugar, pues, el desenlace es una fórmula: la transubstanciación y la fiesta eucarística. Gérard Genette hace una distinción entre narración y descripción. El francés también registró una espacialidad en la literatura descriptiva:

La narración se vincula con acciones o acontecimientos considerados como puros procesos y, por ello mismo, pone el acento en el aspecto temporal y dramático del relato; la descripción, por el contrario, porque se detiene en objetos y seres considerados en su simultaneidad y porque enfoca sus procesos como espectáculos, parece suspender el curso del tiempo y contribuye a desplegar el relato en el espacio ${ }^{9}$.

El lenguaje traiciona la realidad porque convierte la temporalidad de la consciencia en espacio ${ }^{10}$.

Se pueden dividir los discursos literarios de este auto en dos tipos: los que avanzan la historia por medio de la narración y los que se detienen momentáneamente para establecer una espacialidad discursiva por medio de la descripción. La siguiente tabla demuestra las distintas divisiones propuestas por los autores mencionados en este estudio. Es importante notar que las definiciones propuestas por los autores considerados dividen la literatura de la misma manera, o sea en dos grandes ramas:

\begin{tabular}{|l|l|}
\hline Diacrónica & Sincrónica \\
\hline Tiempo (Frank) & Espacio (Frank) \\
\hline Narración (Genette) & Descripción (Genette) \\
\hline Literatura representativa (Scholes \&Kellogg) & Literatura ilustrativa (Scholes \&Kellogg) \\
\hline
\end{tabular}

\footnotetext{
7. Frank, 1991, p. 71

8. Frank, 1991, p. 75

9. Genette, 2013, p. 143

10. Frank, 1991, p. 127.
} 
Divido la presencia de Ut pictura poesis en tres tipos. La primera es cuando la autora hace mención en las acotaciones de alguna pintura o imagen que habría estado presente en la consciencia colectiva de los receptores. La segunda es la descripción de emblemas específicos, conocidos en la época que también habría provocado una imagen viva en la mente de los lectores. La tercera y más compleja es la descripción lograda sincrónicamente por la construcción mental paulatina de una imagen en el espacio. En la descripción hay una suspensión temporal del entendimiento hasta que todas las partes estén ensambladas y se plasman en el espacio mental del receptor.

Las personificaciones, metáforas y alegorías que se construyen en los autos de sor Juana son plásticas. Las personificaciones mitológicas son metáforas y las alegorías relacionadas con su representación, son metáforas dramatizadas. En la loa calderoniana a El sacro Parnaso de 1659, un personaje llamado Alegoría presenta su fisonomía artística:

\author{
Soy \\ (si en términos me defino) \\ docta Alegoría, tropo \\ retórico, que expresivo, \\ debajo de una alusión \\ de otra cosa, significo \\ las propiedades en lejos, \\ los accidentes en visos, \\ pues dando cuerpo al concepto \\ aun lo no visible animo ${ }^{11}$.
}

Las técnicas pictóricas de perspectiva creadas por «lejos» $\mathrm{y}$ «viso» sugieren distancia y contorno y hacen posible la ilusión de tres dimensiones en un 'lienzo' de dos dimensiones. La metáfora de perspectiva plástica utilizada por Alegoría apunta a una consciencia de que el lenguaje figurativo del auto es visual de la misma manera que la pintura: traduce una realidad trascendente a los términos limitados del espacio humano ${ }^{12}$.

La literatura renacentista y áurea es una literatura altamente figurativa, simbólica y alegórica. Por esto no intenta duplicar la realidad sino un aspecto de la realidad, concertado simbólicamente por las convenciones literarias. Los autos sacramentales son obras altamente estilizadas. Dentro de este contexto se inserta El divino Narciso de sor Juana Inés de la Cruz que es, por ser auto sacramental: «la culminación del teatro barroco como fusión de las artes (pintura, escultura, música, poesía)» ${ }^{33}$. Sor Juana seguramente sabía de los nuevos «escenarios en perspectiva procedentes de |talia» ${ }^{14}$ y quiso replicarlos en su obra por medio de palabras. Como La fiera, el rayo y la piedra de Calderón, El divino Narciso demues-

\footnotetext{
11. Cit. en Kurtz, 1991, pp. 52-53.

12. Kurtz, 1991, pp. 54-55.

13. Arellano, 2000, p. 35.

14. Arellano, 2000, p. 46.
} 
tra también «plurimembraciones estilísticas y [...] el uso de deícticos que organizan la mirada del espectador en medio del despliegue gongorino de imágenes y sonoridades poéticas» ${ }^{15}$.

En su obra The Play of Allegory in the Autos Sacramentales de Pedro Calderón de la Barca, Barbara Kurtz sugiere que la reconstrucción de los espacios evocados por las alegorías en el auto sigue una lógica mística propuesta por san Ignacio de Loyola. En una de las últimas manifestaciones del pensamiento mágico medieval, Loyola propone una recreación meditativa de las escenas sagradas. La Compañía de Jesús y el tipo de espiritualidad propuesta por Loyola en sus Ejercicios espirituales tuvieron una influencia grande sobre sor Juana y Calderón, pues, el contacto de ellos con la Compañía era extenso y sus conocimientos de las enseñanzas jesuitas eran profundos ${ }^{16}$. La evocación del compositio ignaciano sugiere una técnica meditativa convertida en una poética de la espacialidad.

\section{ESPACIO Y TIEMPO EN LA LITERATURA}

El auto sacramental es una concentración lingüística de alusiones a la espacialidad. El texto escrito trama un entendimiento tridimensional del desarrollo, elemento importante por su función pedagógica y evangelizadora: «Al misterio se accede a través de la visualización alegórica, en la que se deja sentir la influencia de la literatura emblemática» ${ }^{77}$. Como san Pablo, sor Juana acentuó que el medio para adquirir la fe es por el oído, pero en el Barroco hubo una nueva evaluación de la vista como medio de alcanzar la fe. «Sor Juana sabe que la fe entra por el oído, pero reconoce que la naturaleza humana se "inclina a objetos visibles". Ya Calderón, en su Deposición a favor de los profesores de pintura (1677), habla de las "ventajas que \|leva el sentido de la vista al del oído"»18. Se formula el significado espacialmente, en un momento, y no como una secuencia. Hay un conjunto de correspondencias que se relacionan independientemente de la secuencia temporal de la trama ${ }^{19}$.

En su análisis del soneto «Este que ves, engaño colorido» de la Décima Musa, José Pascual Buxó aprecia la traducción de lo intelectual a lo visual cuando asevera:

La hermosura de la imagen que los ojos contemplan en la tela y, gracias a cuya perfección, confunden con el mismo ser representado, es la consecuencia de un engañoso razonamiento silogístico que, en vez de conceptos verbales, utiliza la gradación de los colores y el resplandor de las luces para convencer al entendimiento con su falaz verdad 20 .

Los «conceptos verbales» son traducidos a «la gradación de los colores» que indica la transición de la diacronía, el lenguaje en el tiempo, a la sincronía, el lenguaje

\footnotetext{
15. Arellano, 2000, p. 47.

16. Kurtz, 1991, p. 170.

17. García, 1998, p. 210.

18. García, 1998, p. 210.

19. Frank, 1991, p. xiii.

20. Pascual Buxó, 1995, p. 320
} 
en el espacio. Además, el silogismo denota un acto sincrónico. Las premisas son diacrónicas pero la conclusión lógica lo convierte en un tapiz, que se esparce por medio de colores, comprehendidos espacialmente.

Las imágenes plásticas predominan en los textos sorjuaninos. La monja «aspira a lograr el efecto de enargeia o viveza representativa [...] dirigida a apelar a los sentidos de la audiencia, especialmente la vista» ${ }^{21}$. En su análisis de los ovillejos de sor Juana, Jorge Checa también refiere al aspecto espacial del ekphrasis como un:

«recurso tendente a interrumpir la temporalidad del discurso, a congelarlo cuando [el discurso] lleva a cabo una exploración de carácter espacial» [...] el impulso ekphrástico entra en conflicto, por un lado, con el flujo inherente a la índole no simultánea, sino sucesivo, del lenguaje, mientras que, por otro lado, extiende el campo donde la noción de ekphrasis se acomoda: aparte de aludir a la descripción de objetos usualmente artísticos, la ekphrasis, en una segunda acepción, puede también señalar la pretensión espacial, o cabe decir monumental, de ciertos poemas, en la medida en que busquen presentarse como artefactos cerrados, autocontenidos, ostentatorios de su propia sustantividad22.

La naturaleza ekfrástica de El divino Narciso lo convierte en monumento.

\section{MENCIONES DE LA PINTURA}

En un largo soliloquio, Eco, que representa a Lucifer, discurre sobre los fracasos del ser humano y de sus triunfos espirituales. Entre los triunfos, habla de Abraham «aquel monstruo / de la fe y de la obediencia» (vv. 551-552) ${ }^{23}$. En esta sección, la acotación indica: «Pasa Abraham, como le pintan» (entre vv. 562-563). Circularon en la Nueva España, biblias italianas, alemanas y francesas, profusamente ilustradas del siglo XVI. Los grabados sirvieron como modelos para pinturas y dibujos locales. La referencia física a Abraham que ora «como le pinten» habría sido fácilmente replicable en la mente de los lectores. El acervo visual de este personaje era tan difundido que los indígenas modelaban sus propios pinturas y dibujos según los patrones europeos de estos textos ${ }^{24}$. 




Este dibujo es de la Biblia germánica que circulaba en América en los siglos XVI y XVII cuyas imágenes tuvieron una influencia marcada sobre artistas de las colonias, incluyendo artistas indígenas ${ }^{25}$. En la siguiente glosa del Antiguo Testamento, apela a la vista con evocaciones como:

mirad a Abel

que las espigas agrega

y los carbones aplica,

para hacer a Dios ofrenda (vv. 535-538)

La acotación narra «Ábrase el carro segundo; y va dando vuelta, en elevación, Abel, encendiendo la lumbre; y encúbrese, en cantando» (entre vv. 538-539). Refiere didácticamente a un grabado parecido a este que los lectores habrían reconocido por las fuentes bíblicas ilustradas:

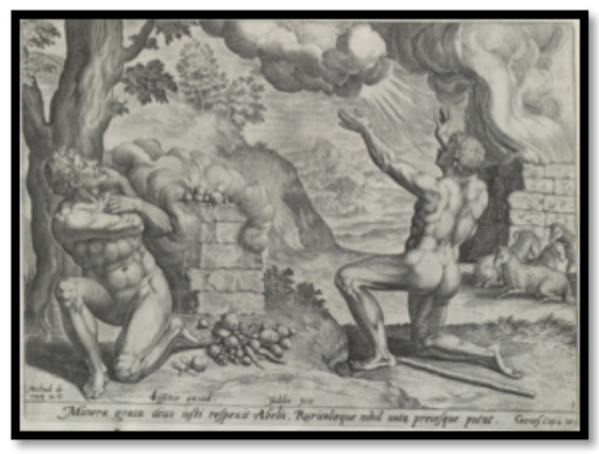

La inclusión de emblemas era una técnica áurea muy común. Son una versión híbrida del Ut pictura poesis porque implican y están compuestos de imagen y palabra. Un ejemplo de esto es la referencia de Gracia, que representa a la Virgen María, como una fuente sellada:

GRACIA ¿Cómo? Siguiendo mis plantas,
y llegando a aquella fuente,
cuyas cristalinas aguas
libres de licor impuro,




siempre limpias, siempre intactas
desde su instante primero,
siempre han corrido sin mancha.
Aquésta es de los cantares
aquella fuente sellada
que sale del Paraíso,
y aguas vivíficas mana (vv. 1026-1036).

Revisando el siguiente emblema, apreciamos los versos de Gracia como un fiel Ut pictura poesis de él.

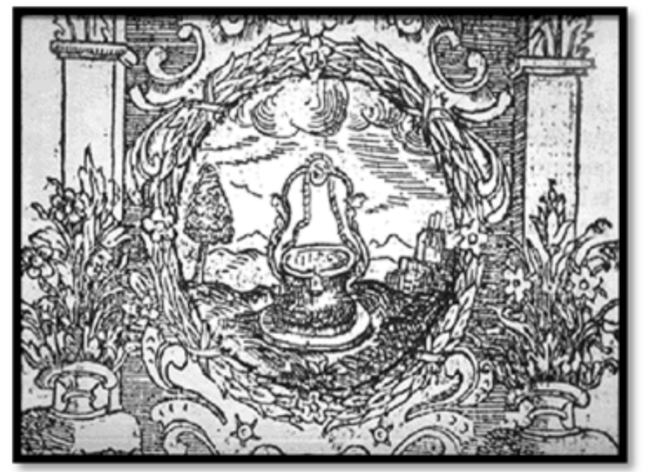

Antonio Bernat Vistarini y John T. Cull, Enciclopedia de Emblemas Españoles Ilustrados. Emblema 1366.

La fuente del emblemista es el Cantar de los Cantares «Fons hortorum: puteus aquarum viventium, quae fluunt impetu de Libano» ${ }^{26}$. Implícito en el emblema es el subscriptio que viene del texto María Pozo de Aguas Vivas, fol. 87v, y reza: «El pozo y fuente sellada / no recibió sus cristales / de sulfúreos minerales»27. Los emblemas son «metáforas verbales y visuales» 28 y, por lo tanto, apuntalan a los aspectos temporales y espaciales del lenguaje. Sor Juana toma conceptos metafísicos e intangibles y los convierte en objetos monumentales. Así también es el emblema: plasma en un conjunto visual conceptos complejos. Cosifica fenómenos intelectuales para que sean asibles como en el Primer sueño cuando cosifica «la noche, el viento, los átomos, el susurro» ${ }^{29}$.

La tercera categoría demuestra la dimensión espacial del lenguaje por medio de palabras individuales explayadas: la imagen completa se construye sincrónicamente después de una suspensión momentánea de comprensión. En cuanto el lector termine la lectura de los cuatro siguientes versos, se plasman espacialmente en una figura plástica mental.






$\begin{array}{ll}\text { GENTILIDAD } & \text { A su bello resplandor } \\ & \text { se para el claro farol } \\ & \text { del sol; y por ver su cara, } \\ & \text { el fogoso carro para } \\ & \text { mirando sus perfecciones (vv. 180-184). }\end{array}$

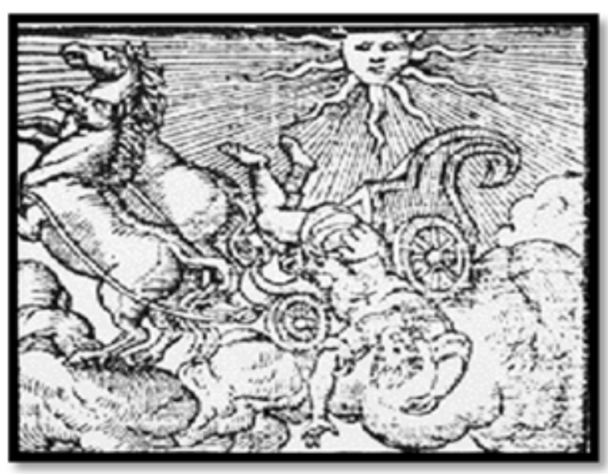

Antonio Bernat Vistarini y John T. Cull, Enciclopedia de Emblemas Españoles Ilustrados. Emblema 662.

Faetón quiere que Apolo acredite al mundo que es verdaderamente su padre dejándolo usar su carro. Primero, consiente el deseo de Faetón, pero demasiado tarde se arrepiente: «Mira los rostros / aquí míos, y ojalá tus ojos en mi pecho pudieras / inserir y dentro desprender los paternos cuidados» ${ }^{30}$. En referencia al personaje favorito de la monja, Faetón, se dibuja en estos versos, en el momento exacto en que el hijo de Apolo logra su deseo de llegar a la par del Sol, pero también es, en este momento, que su carro ya se halla fogoso, o sea, a punto de incinerarse.

Las letras humanas de la gentilidad son vislumbres de las letras sagradas, según el pensamiento de la época, ejemplificado por Pérez de Moya en su Philosofía secreta (1585), entre otros. Dios/Apolo hizo el ser humano/Faetón en su imagen. Cuando Faetón se acerca al «claro farol», el farol «se para a su bello resplandor», embelesado por su creación. De tal manera, Faetón «para» y es convertido en «fogoso carro» por haber visto las perfecciones de la cara de su padre, el Sol. En este segmento, los versos de Gentilidad revelan que el mirar a su creador es un acto destructivo. En el momento de descubrir la beldad de su creación, Faetón es destruido por los poderes negativos de su padre pagano, Apolo. En contraste, en la última parte del auto, el ser humano, creado a la imagen de su padre Dios, es salvado en el espejo de la fuente cuando Cristo/Narciso mira a su propia imagen en él, Naturaleza humana. El mito pagano de Gentilidad representa destrucción mientras la contrafacción barroca cristiana es la salvación. Para demostrar la diferencia entre la edificación poética representativa/temporal y la ilustrativa/espacial, basta con comparar dos interlocuciones de Gentilidad: 


\begin{tabular}{|l|l|}
\hline $\begin{array}{l}\text { Literatura representativa (Scholes \&Ke- } \\
\text { llogg) }\end{array}$ & Literatura ilustrativa (Scholes \&Kellogg) \\
\hline Tiempo (Frank) & Espacio (Frank) \\
\hline $\begin{array}{l}\text { Y pues su beldad hermosa, } \\
\text { soberana y prodigiosa, } \\
\text { es de todas la mayor, } \\
\text { cuyo sin igual primor } \\
\text { aplauden los horizontes (vv. 166-170). }\end{array}$ & $\begin{array}{l}\text { A su bello resplandor } \\
\text { se para el claro farol } \\
\text { del sol; y por ver su cara, } \\
\text { el fogoso carro para } \\
\text { mirando sus perfecciones (vv. 180-184). }\end{array}$ \\
& \\
\hline
\end{tabular}

Hay espejos auditivos (Eco), figurativos (Narciso y Gracia) y literales (Faetón y el Sol) que se insertan dentro de «la compleja estética de los espejos del Barroco» ${ }^{37}$. La imagen es un ejemplo del lenguaje sincrónico, el tiempo del lenguaje convertido en espacio. Por medio de un espejismo, la figura es creada por el Sol que se detiene para ver el «bello resplandor» de su hijo, Faetón. La comprensión hermenéutica se suspende hasta que el reflejo metafórico se complete con el «carro fogoso» o sea, Faetón incendiado a punto de desplomarse a la tierra por haber visto la perfección de su creador Apolo/Sol dios de la luz y la verdad, una vislumbre del Dios cristiano.

\title{
LA ESPACIALIDAD METAFÓRICA DEL ESPEJO Y EL ECO: EL METARREFLEJO
}

El lenguaje poético del reflejo se manifiesta en el espejo y el eco. El reflejo forma parte de los intersticios filosóficos y teológicos de la trama de El divino Narciso pero también, usa repeticiones poéticas que contienen espejos y ecos que yo llamaría la poética del metarreflejo. Defino el metarreflejo como una técnica retórica para representar al leitmotiv del reflejo del doble. Las frases: «Dios creó al hombre a su imagen» y el hombre «está hecho a la imagen de Dios» se plasman en Dios, hecho hombre, en la figura de Cristo. Narciso, figura cristológica en este auto, es otro doble porque representa a Cristo. En preparación para el desarrollo de la analogía, Gracia advierte a Naturaleza humana:

\author{
Procura tú que tu rostro \\ se represente en las aguas, \\ porque llegando él a verlas \\ mire en ti su semejanza; \\ porque de sí se enamore (vv. 1075-1079)
}

El espejo multiplica por medio del reflejo a la imagen. El espejo alude a dos cuerpos en el espacio: uno en tres dimensiones y el otro en dos. Además del juego de intertextualidad entre el auto y el Antiguo Testamento y la Metamorfosis de Ovidio, el espejo y el reflejo siempre dan entrada a una pausa momentánea para crear una 
imagen, un doble. Este acto desvía el lenguaje de su naturaleza diacrónica y temporal a su manifestación sincrónica y espacial.

\author{
Éste, pues, hermoso asombro, \\ que entre los prados floridos \\ se regalaba en las rosas, \\ se apacentaba en los lilios, \\ de ver el reflejo hermoso \\ de su esplendor peregrino, \\ viendo en el hombre su imagen, \\ se enamoró de sí mismo (vv. 1982-1989).
}

Toda la mecánica del auto yace en el doble, en la semejanza, en la imagen gemela de un espejo. Menciones de espejos, reflejos y semejanzas forman un leitmotiv y manifiestan la trama filosófica y teológica de la obra. Formas de la palabra «mirar» se usan 41 veces, «ver» 44 veces, «parecer» 15 veces, «semejanza» 10 veces, «imagen» 13 veces, «ojos» 17 veces, más palabras como «espejo», «reflejo», «estatua de sí misma», y otros vocablos de la misma índole, también figuran en el texto, apelando al sentido de la vista.

Los ovillejos ecoicos ${ }^{32}$ son espejos auditivos. Los segmentos ecoicos se transcriben diacrónicamente, palabra aislada por palabra aislada, sin entender qué quiere decir Eco mientras diserte. Una vez acumuladas las palabras individuales de Eco, se reestiman las palabras individuales ahora recolectadas en una oración comprensible. Como afirmó Frank, hay una suspensión momentánea de la comprensión metafórica hasta que los ovillejos sean compuestos y Eco puede formar una oración:

$\begin{array}{ll}\text { NARCISO } & \text { Es insufrible el tormento } \\ \text { ECO } & \text { Tormento. } \\ \text { NARCISO } & \text { de los dolores que paso } \\ \text { ECO } & \text { Paso. } \\ \text { NARCISO } & \text { en rigor tan insufrible; } \\ \text { ECO } & \text { Insufrible. } \\ \text { NARCISO } & \begin{array}{l}\text { pues en mi pena terrible } \\ \text { n en el dolor de que muero, }\end{array} \\ & \text { no gozando lo que quiero, } \\ \text { LOS DOS } & \text { Tormento paso insufrible ( } \mathrm{vv} . \text { 1469-1475). }\end{array}$

32. Sobre los ovillejos ecoicos, ver Alatorre, 1990, pp. 644-674, y Méndez Plancarte, III, 1994, p. 541. 
Una vez que Eco haya formado un verso, recomienzan de nuevo los ecos individuales hasta llegar a la siguiente composición sincrónica de una oración completa, y así, sucesivamente. Por fin, Eco consigue recolectar más palabras individuales y logra una composición sincrónica acabada:



La composición de los ovillejos ecoicos es un ejemplo de la transformación de la construcción poética lineal a la acumulación de palabras para formar una oración entendible: es una analogía de la transición de la diacronía a la sincronía. Además de las implicaciones plásticas, los ecos recitados por Eco son sintomáticos de una «perversa circularidad», un «narcisismo diabólico» y representa la idolatría ${ }^{33}$. La idolatría es «una "reificación" o "fetichización" de los signos y se convierte en "[p]risionero de su autorreflexibilidad, y [...] deja de ser un puente para el conocimiento divino"»34.

\section{CONCLUSIONES}

Sor Juana Inés de la Cruz produjo una lírica plástica por medio de un lenguaje que se comprende sincrónicamente. Bajo la influencia de Calderón de la Barca, la monja también incorpora la aprehensión estética de san Ignacio de Loyola en la compositio de las imágenes sensoriales que componen sus obras ${ }^{35}$. Si la obra El divino Narciso se creó bajo esta poética de recreación lingüística del espacio dramático, un examen completo del auto incluiría el aspecto espaciotemporal de las figuras literarias. El auto se extiende en el tiempo diacrónicamente pero se interrumpe sincrónicamente con pequeñas escenas espaciales. La referencia a imágenes conocidas por los lectores, la ut pictura poesis de los emblemas, las imágenes sonoras ecoicas que resultan en una comprensión sincrónica de la figura después de una acumulación de versos diacrónicos, aportan una clase de dimensión espacial. Creaciones de un mundo vívidamente visual, los autos sacramentales como El divino Narciso de sor Juana son pinturas poéticas de lo inefable. Incorporan el «símbolo místico» neoplatónico «como trasunto que es de los atributos inexpresables de Dios» ${ }^{36}$. Los autos conectan «sucesos muy lejanos [y] quiebra en ocasiones el desarrollo lineal de su narración y produce un efecto de simultaneidad»37.

El divino Narciso utiliza un lenguaje ilustrativo que forma un conjunto espaciotemporal. Las menciones de la pintura crean pausas en la comprensión para poder reformular en la memoria las partes para recrear una totalidad de la imagen. Las




descripciones de emblemas, un verdadero ut pictura poesis, es una acumulación de elementos visuales y lingüísticos que requieren de una lectura sincrónica. Los espejos y ecos constituyen una capa polisémica que se refieren a conceptos neoplatónicos y herméticos que detienen el flujo del lenguaje y crean un pozo profundo de significados.

\section{BibliografíA}

Alatorre, Antonio, «Perduración del 'ovillejo cervantino'», Nueva Revista de Filología Hispánica, XXXVIII, 2, 1990, pp. 643-674.

Arellano, Ignacio, «El teatro de Corte de Calderón», en Atti della tavola rotonda: La singolarità storica e estética di "La Púrpura de la Rosa" di Calderón de la Barca, ed. María Luisa Tobar, Messina, Armando Siciliano Editore, 2000, pp. 32-52.

Arenal, Electa, «Enigmas emblemáticos: El Neptuno alegórico de Sor Juana Inés de la Cruz», en Sor Juana y su mundo: una mirada actual, coord. Carmen LópezPortillo, México, Universidad del Claustro de Sor Juana/FCE, 1998, pp. 85-94.

Arnheim, Rudolf, El pensamiento visual, Barcelona, Ediciones Paidós Ibérica, 1998.

Arroyo, Susana, «El poema Primero Sueño», en Sor Juana y su mundo: una mirada actual, coord. Carmen López-Portillo, México, Universidad del Claustro de Sor Juana/FCE, 1998, pp. 98-103.

Bernat, Antonio y Cull, John, Emblemas españoles ilustrados, Madrid, Akal, 1999.

Checa, Jorge, «Al margen del retrato: Ios ovillejos de Sor Juana», en Sor Juana y su mundo: una mirada actual, coord. Carmen López-Portillo, México, Universidad del Claustro de Sor Juana/FCE, 1998, pp. 184-192.

Checa, Jorge, «El divino Narciso y la redención del lenguaje», Nueva Revista de Filología Hispánica, XXXVIII, 1, 1990, pp. 197-217.

Escalante, Pablo «Pintar la historia tras la crisis de la Conquista», en Los pinceles de la historia. El origen del Reino de la Nueva España, 1680-1760, México, INBA, 1999, pp. 24-49.

Frank, Joseph, The Widening Gyre, New York, Rutgers, The State University, 1963.

Frank, Joseph, The Idea of Spatial Form, New Brunswick/London, Rutgers University Press, 1991.

García Valdés, Celsa Carmen, «Teatralidad barroca: Ias loas sacramentales de Sor Juana», en Sor Juana y su mundo: una mirada actual, coord. Carmen LópezPortillo, México, Universidad del Claustro de Sor Juana/FCE, 1998, pp. 207218.

Genette, Gérard, Fronteras del relato, ed., e-book browse https:// textosontologia.files.wordpress.com/2012/09/fronteras-del-relato.pdf [Fecha de consulta 19/07/2016] 
Kurtz, Barbara, The Play of Allegory in the "Autos Sacramentales" of Pedro Calderón de la Barca, Washington, D.C., The Catholic University of America Press, 1991.

Lee, Rensselaer, «Ut pictura poesis: The Humanistic Theory of Painting», The Art Bulletin, 22, 1940, pp. 197-269.

Méndez Plancarte, Alfonso, «Notas», Obras completas de Sor Juana Inés de la Cruz, III, «Autos y Loas», Edición, prólogo y notas de Alfonso Méndez Plancarte, México, Fondo de Cultura Económica, 1995.

Olivares, Rocío, «Apologética, mítica y mística en El Divino Narciso, de Sor Juana», Espéculo. Revista de Estudios Literarios, 46, 2010, s. p.

Pascual Buxó, José, «Sor Juana Inés de la Cruz: entre Heráclito y Demócrito», en Coloquio Internacional. Sor Juana Inés de la Cruz y el pensamiento novohispano, México, Instituto Mexiquense de Cultura y Universidad Autónoma del Estado de México, 1995, pp. 311-323.

Scholes, Robert y Robert Kellogg, The Nature of Narrative, Oxford, Oxford University Press, 1968.

Juana Inés de la Cruz, sor, El divino Narciso, ed. Robin Ann Rice, Pamplona, Eunsa, 2005.

Van de Guchte, Maarten, «Invención y asimilación. Los grabados europeos como modelo para los dibujos de Felipe Guaman Poma», trad. Patricia Díaz Cayeros, Revista de la Dirección de Estudios Históricos del Instituto Nacional de Antropología e Historia, 29, octubre 1992-marzo 1993, pp. 143-160. 